\title{
Towards EFL Reactive Teaching: From Lesson Plan pro Forma to Affordance-6ased Planning
}

\section{Dr. Osama Hassanein Sayed}

Assoc. Prof. in Curriculum and Methods of TEFL, Faculty of Education in the New Valley, Asyut University

\section{Abstract:}

7 he current study aimed at exploring the effectiveness
of affordance-based teaching on EFL students'
general English language performance. Sixty four freshmen in two classes of the preparatory year at the Northern Borders University participated in this study. One class with 31 students was assigned to the experimental group while the other class with 33 students was assigned to the control group. Students in both classes were all in literary path, registered in English 1 course (Code: 1001101). Affordance-based teaching that utilizes lesson contingent affordances and various learning opportunities offered by language learning tasks, was used with the students of the experimental group whereas, those of the control group were taught in the usual way. A pre-post general English language test was used to assess participants' general English language performance before and after the intervention. Results revealed that experimental group students outperformed their counterparts of the control group in the posttest of general English language performance. Based on the results attained, some recommendations were made; A change is needed in EFL teachers practices, from teaching to managing learning and from teaching pre-planned specific teaching points to identifying and managing learning opportunities. Instead of basing their lesson plans on specific learning outcomes, they should plan for richness of opportunity. In addition, EFL teachers should overcome their fear of going off script and they should be prepared to cope with unexpected classroom events and help their students to act on them.

Keywords: Affordance, Learning Opportunity, Teacher Contingent Behavior, Lesson Plan pro Forma.

\section{Introduction}

Language classrooms are "complex, context dependent cultures that are replete with unanticipated moments for generating authentic interactions and learning opportunities" (Chick, 2015, p. 40). In addition, in the complex and dynamic 
system inside the foreign language classroom, students, not only participate in the construction of knowledge emerging from their shared experience, but also exercise a great influence on one another (Kindt, Cholewinski, Kumai, Lewis \& Taylor, 1999; Inan \& Fidan, 2013). In view of this, EFL teachers need to reconsider the way they plan and teach. In this respect, Shpancer (2004) points out that using a flexible approach in lesson planning allows the teacher to "more easily seize on and develop emerging, unscripted moments or moods in the classroom" (p. 28). He further clarifies that such unpredicted occasions that arise spontaneously from within "the classroom journey offer opportunities for strong educational and personal benefits, in the same way that travelers to a foreign country often gain more from chance encounters with the locals than from sticking to the planned itinerary" (p. 29). Supporting this, van Lier (2008, p. 163) claims that language learning "depends on the activity and the initiative of the learner, more so than on any "inputs" that are transmitted to the learner by a teacher or a textbook". In saying so, van Lier (2008) does not diminish the role played by textbooks and teachers but he puts extra emphasis on student actions, interactions and lesson affordances, rather than on textbooks. According to Waring (2011), language learning occurs in in the ongoing expansion of language use via student initiatives taking place inside the EFL classroom. Students expand their participation and gain access to several learning opportunities by taking initiatives, often against the teacher's agenda, to "joke, resist, redirect, plead, persuade, assert stances, display knowledge, seek and pursue understandings or import casual conversations into the classroom" (p. 215).

Unfortunately, for several decades, there has been a strong convection among language teachers grounded on a commonsense view of language teaching and learning that language lessons should be based on a pre-specification of specific things to be taught (Allwright, 2005). Accordingly, "most commonly used lesson plan pro formas in language teacher education are inappropriately premised on an outcomes-based approach to teaching" (Anderson, 2015, p. 228) that contradicts 
what we know about how languages are learnt. As a result, the IRF sequence (Teacher Initiative-Student Response-Teacher Feedback), where the learner is invariably positioned as a respondent who assists in implementing the teacher's pedagogical agenda, is a cornerstone in classroom discourse" (Waring, 2011, p. 201).

According to the academic classroom research results, we have reason to be worried about the practical value of basing EFL lessons mainly on specific teaching points (Crabbe, 2003; Allwright, 2005; Crabbe, 2007; van Lier, 2008; Waring, 2011; Anderson, 2015; Chick, 2015; among others). Until very recently, "an externally decided, predetermined focus on a discrete aspect or function of language, as a lesson aim, still appears to be the principal unit around which most pre-service lesson planning literature is based" (Chick, 2015, p. 53). Teachers usually pay scant attention to the fact that learners may learn more than has been previously-planned and explicitly taught to them (Allwright, 2005). Moreover, the pro formas currently used by EFL teachers generally reflects a trans missive, outcomesoriented manner of planning that contradicts with how second/foreign languages are learnt since "learners do not necessarily learn according to the teacher's objectives, and the learning that actually occurs in each learner's head is often difficult to predict or control" (Lightbown \& Spada, 2013, as cited in Anderson, 2015, p. 229).

Researchers, together with language instructors, have come to recognize, more and more, the importance of emphasizing teachers' contingent behavior in the classroom and the central role played by learners as vigorous agents jointly co-constructing their lessons and managing them with their teachers (Allwright, 2005; van Lier, 2008; Waring, 2011; Foster, 2015; among others). Accordingly, the kind of planning that is most needed to language teaching and learning is "planning for richness of opportunity and especially for understanding, not planning to determine highly specific learning outcomes" (Allwright, 2005, p. 10). To better do their jobs, foreign language teachers need to 
plan for affordances and respond to them once they happen; they should be both proactive and reactive, the 'catalysts of learning opportunities' (Anderson, 2015). Instead of planning for precise target learning outcomes, EFL teachers and learners should work at the level of "managing learning opportunities, trying to make them as potentially productive for themselves as possible, by following their current understandings of what seems most promising and by working to deepen their understandings of life in the language classroom" (Allwright, 2005, p. 24).

It is worth mentioning that, learning opportunities may be teacher-initiated, as well as learner-initiated, or created by chance rather than careful planning (Allwright, 2005; Anderson, 2015). According to Crabbe (2007), "to process comprehensible input is a learning opportunity, as is to engage in interaction, or rehearse specific aspects of communication for greater automaticity" (p. 118). In addition, learning opportunities may arise during or as a consequence of the lesson (Anderson, 2015). Categories of good language learning opportunities derived from current second language acquisition research includes input, output, interaction, feedback, rehearsal and language understanding (Crabbe, 2003).

Instead of locking in old teaching techniques, EFL teachers and course designers, according to Crabbe (2003) should look for input, as well as interaction opportunities that learners are likely to need and how can feedback opportunities be built in. In the classroom context, language learning tasks usually "offer many more learning opportunities than are actually exploited" (Crabb, 2007, p. 119). During engagement in a lesson task or an activity, students' goals and actions sometimes differ from those planned by their teacher and consequently, they use language to refuse or subvert certain step/s in the given task or activity. Here, the students' language use is not something intended by the teacher. Instead, it is an instance of the emergence of an unplanned affordance for new language use (Ohashi, 2005). While the learning outcome is a description of teacher intention, the learning opportunity is a prediction of learner development, one 
that may or may not occur depending on the lesson affordances (Anderson, 2015). Supporting this, Crabbe (2007, p. 120), puts it very clear that "much of the full potential of tasks must lie not in the programmed activity but in what the learners do for themselves".

\section{Context of the Problem}

Academic classroom research results, over the past decades, casted doubt on the actual educational value of pointbased teaching and provided reasonable evidence that classroom language learning is essentially idiosyncratic and unpredictable and learners may get from lessons through the numerous learning opportunities that arise (Kindt, Cholewinski, Kumai, Lewis \& Taylor, 1999; Crabbe, 2003; Allwright, 2005; van Lier, 2008; Anderson, 2015; Chick, 2015; among others). However, among the majority of the EFL lesson plans used worldwide, as claimed by Anderson (2015), very "few made any concessions to allow for affordance" (p. 230). Although helping learners to manage their learning is the main and most important role of the EFL teacher, it is unfortunately, a0 forgotten aspect in the communicative classroom (Crabbe, 2007). "Despite being exposed to a knowledge base that highlighted the positive aspects of reactive teaching, the LTs, according to Chick (2015), were often more comfortable in the role of knowledge transmitter. A role for which they could take comfort in knowing they could prepare and plan for" (p. 38).

On the other hand, academic classroom research results, over the past decades, revealed that an emphasis on teaching points was not only inefficient in itself, but also seemed to "hinder teachers and learners from making the most of opportunities to have really productive, though previously unplanned, episodes of teaching and learning" (Allwright, 2005, p. 14). Due to teachers' "unrealistic battle against the clock that is so often a critical factor in the success of an outcomes-oriented lesson" (Anderson, 2015, p. 232), most planned affordances turn to be weak ones that rarely lead to new learning. Students fall to achieve what is intended in an activity. Even though they manage 
to perform what is expected, their performance appears superficial, doing what is expected rather than understanding and assuming new language use (Ohashi, 2005). Supporting this, Chick (2015), affirms that:

The emphasis on training learner teachers to plan for specific outcomes, such as a pre-selected language point, and basing postteaching feedback discussions around the achievement, or otherwise, of those outcomes, can appear incongruous with many current views of good practice in managing learning (p. 53).

In this respect, Allwright (2005) wonders whether language teachers should abandon planning altogether, since what learners get from a lesson is so unpredictable? And he affirms that what should be reasonably abandoned is the idea of narrow teaching points as the basic unit of planning. Chick (2015, p. 39) assures that "relinquishing control of a lesson may lead to unanticipated opportunities for learning to occur". Anderson (2015) advises teachers to prepare for and respond to the unpredictable occasions and affordances of the lesson. Crabbe (2007, p. 117), claims that underlying each language learning task is a collection of learning opportunities or potential learning activities not all of which are exploited by teachers or by learners. Further, Crabbe (2007) proposes that in order to better exploit the several learning opportunities offered by language learning tasks, such opportunities "need to be identified and modeled for learners in order to encourage them to manage their learning independently" (Ibid., p. 117).

While observing in-service EFL teachers in some intermediate schools in Arar, as part of a teacher development program offered by the Deanship of community service at the Northern Borders University, it was found by this researcher that most of those teachers, especially novice one, stick rigidly to the lesson plan pro formas they use. They often fail to exploit the opportunities for spontaneous language work or unpredictable learner input and they prefer the comfortable role of knowledge transmitter for fear of going off script. 
Drawing on the recommendations of several researchers and language teachers (Crabbe, 2003; Shpancer, 2004; Allwright, 2005; Crabbe, 2007; Anderson, 2015; Chick, 2015; among others), the current study attempts to investigate the effect of using an affordance-based approach which utilizes learning opportunities offered by language learning tasks as well as unexpected situations in which students show interest on EFL students' general language performance.

\section{Problem Statement}

Instead of seizing upon unexpected events that arise inside classrooms and making them instructive, most EFL teachers avoid dealing with them. Their perceptions of the lesson event itself are much influenced by the lesson plan pro formas they use and consequently, they adhere rigidly to a pre-planned sequence of events. As a result, they fail to help their students see and act on the numerous learning opportunities afforded by language learning tasks. Hence, this study investigates the effect of using an affordance-based approach that utilizes lesson contingent affordances and learning opportunities on EFL students' general language performance.

\section{Study Questions}

The study tried to answer these questions:

1. What is the effect of affordance-based teaching on EFL students' general language performance?

1. What is the effect of affordance-based teaching on EFL students' reading skill?

2. What is the effect of affordance-based teaching on EFL students' writing skill?

3. What is the effect of affordance-based teaching on EFL students' listening skill?

4. What is the effect of affordance-based teaching on EFL students' speaking skill?

\section{Study Hypothesis}

The researcher hypothesized the following: 
1. Experimental group students' posttest scores would be higher than their counterparts of the control group in the posttest of general English performance as well as in the four individual skills (listening comprehension, speaking, reading comprehension and writing).

\section{Objective of the Study}

This study tried to:

1. Examine the effectiveness of affordance-based teaching on EFL students' general language performance as well as the four individual language skills.

\section{Study Significance}

This study derived its importance from these considerations:

1. This study is seen as an innovative one that tried to test using affordance-based teaching within formal classroom context.

2. The findings of the current study may draw the attention of foreign language teachers as well as those responsible for curricula development to the necessity of reconsidering the use of lesson plan pro formas which are improperly grounded on an outcomes-based approach to language teaching.

\section{Study Delimitations}

This study was delimited to EFL preparatory year students in literary path at the Northern Borders University, Saudi Arabia. Because of sex segregation imposed in Saudi Arabia, male students were selected to be the participants of this study since the researcher himself is the one who conducted the intervention in order to guarantee effective interaction.

\section{Theoretical Background:}

\section{Affordance}

The concept of affordance had its origins in ecology studies and was coined by the American psychologist Gibson (Menezes, 
2011). According to van Lier (2004, as cited in Anderson, 2015, p. 229), the term 'affordance' refers to "the way in which the learning environment provides opportunities (which may be both positive or negative, effective or ineffective) for the learner to learn". For Fahim (2012) "if the language learner is active and engaged, she or he is likely to perceive linguistic affordances and to bring them into play for the linguistic action" (p. 1277).

In the classroom context, as a sociocultural community in which the teacher and students interact and participate, affordances are "those opportunities for learning/participation arising out of the classroom context" (Ohashi, 2005, p. 69). However, affordances may happen inside or outside the classroom context. (Rosado, 2013). At the same time, language affordances are not the same for all learner. Some contexts offer more learning opportunities and fewer restrictions than others and vice-versa (Menezes, 2011). In the classroom, affordances are either intentionally created or arise naturally and they are perceived either as providing opportunities for learning or as opportunities that can be utilized as such (Ohashi (2005).

It is worth mentioning that, we, as language teachers, must put in mind that "schools alone cannot gather all the necessary affordances for language development and open our students' eyes to the world around them" (Menezes, 2011, p. 69). We should encourage our EFL students to search for affordances outside the classroom and help them to better exploit them for language learning (Fahim, 2012). Supporting this view point, Menezes (2011) points out that affordances outside the classrooms are crucial elements for language learning. He adds that such affordances "manifest themselves in written and oral interactions with other individuals in the inner or in the extended niches and in experiences with cultural productions (books, magazines, songs, movies, games, etc.)" (p. 69).

In this way, learning is not perceived as a transfer of knowledge from the teacher to the students but as emergence. Unplanned or unanticipated learning emerges and takes place whenever the students are actively engaged in the learning 
environment and take up lesson affordances as learning opportunities. Thus, EFL teachers move from teaching to managing learning and replace the teaching points with the learning opportunities.

\section{Learning Opportunity}

A learning opportunity refers simply to a "specific cognitive or metacognitive activity that a learner can engage in that is likely to lead to learning" (2007, p. 118). Learning opportunities are possible acts of either explicit or implicit learning or both that may take place during or as a consequence of the lesson (Anderson (2015). According to Anderson (2015), a learning opportunity is "a prediction of learner development, one that may or may not happen depending on the affordances of the lesson" (p. 231).

In second/foreign language learning, an opportunity for learning can be defined as any activity that possibly leads to an increase in language knowledge or skill. It may include the opportunity to "negotiate meaning in a discussion, to read and derive meaning from a printed text, to explore a pattern in language usage, or to get direct feedback on one's own use of language" (Crabbe, 2003, p. 18). Worth mentioning, language tasks and learning opportunities are "important companion concepts that need to be well understood by teachers and learners alike in order for language learning to be transparent and well managed" (Crabbe, 2007, p. 119). Language tasks, as seen by Anderson (2015), may offer several learning opportunities such as noticing, restructuring of the interlanguage, and proceduralization of knowledge.

\section{Method and Procedures}

\section{Participants}

Sixty four freshmen in two classes of the preparatory year, Northern Borders University, participated in the present study. A class with 31 students was assigned to the experimental group while the other one with 33 students was assigned to the control group. Students in both classes were all in literary path, 
registered in English 1 course (Code: 1001101) and they were all studying New Headway Plus: Special Edition, Beginner (2011), by John and Liz Soars. After discounting drop outs, the students who effectively completed the entire experiment were 59 students. Thirty students in the experimental group and 27 in the control one.

\section{The Design of the Experiment}

The experimental design used in this study was the pretestposttest design. A control group and an experimental group were subjected to a pre/posttest of general English language performance. Affordance-based teaching that utilizes lesson contingent affordances and various learning opportunities offered by language learning tasks, was used with the experimental group students in teaching one of the core textbooks of the English 1 course (see the intervention section for more details). This book is New Headway Plus: Special Edition, Beginner (2011), by John and Liz Soar. It aims at helping students to achieve a general English language proficiency of beginner basic user defined as A1 level on the Common European Framework of Reference for Languages (CEFR). On the other hand, students of the control group were taught the same core book, in the usual way.

According to the study plan of the preparatory year at the Northern Borders University, three contact hours per day are allocated for English (1) course. At the same time, the book contains 14 units. Thus, teaching this book continued for 4 weeks (two units per week).

\section{Research Instruments}

\section{A Pre-posttest of General English language Performance}

A pre-posttest of general English language performance was developed to be used for measuring students' English language performance before and after the intervention (see appendix 1). The test consists of four parts. The first part 
was for measuring students' reading comprehension skills including level of vocabulary, reading for main ideas and reading for details. A reading comprehension passage (195 words) was taken and modified from those free reading passages by PearsonEducation, Inc. accessible at: http://www.Pearson longman.com/ae/marketing/sfesl/tests/grade2.html\#question2. The passage had five questions on it. The questions were of the multiple-choice format (MCQ). The second part was for measuring students' writing skills including stating a main topic, providing supporting details, proper organization, vocabulary use and control of mechanics. Testees were requested to write a single paragraph of about 100 words. The third part was for measuring students' listening skills including understanding the main idea, listening for details and guessing the meaning of unfamiliar lexical items. Materials used in designing this part of the test were taken from the recordings of The British Council at "Professionals Podcast English Listening Downloads Archive", available online at http://top2learn.blogspot.com/2008/04/ professionals-podcast-english-listening.html. An audio file of British English spoken with RP accent and with a normal nativespeaker rate was downloaded and used in designing this test. It was a conversation about renewable energy sources ( 3 minutes 3 seconds). It included five questions of the true-and-false (T/F) item type. Students were asked to decide if the given statements are true or false according to the heard information. The fourth and last part was for measuring students' speaking skills including phonological accuracy, structural accuracy and vocabulary adequacy. Testees were first presented with five spoken biographical questions and were asked to answer each of them orally. After that, Testees were given group of pictures then asked to tell orally the story that these pictures illustrate.

\section{Scoring the Test}

In scoring the reading part of this test, four marks were assigned to each right item. Accordingly, the maximum score of this part is 20 marks. For scoring the writing part, a scoring rubric was devised for this purpose (appendix 2). This rubric 
was aimed to measure five domains. Each of these domains represent a main norm of paragraph writing; i.e. topic sentence, content, organization, vocabulary and mechanics. Two raters participated in scoring each student's paragraph. They independently evaluated the student's writing using the rubric. Therefore, the final score of a student on this part was the average score given by the 2 raters. The maximum score of this part was 20 marks.

In scoring the listening part of this test, four marks were assigned to each right item. Therefore, the maximum score of this part is also 20 marks. Regarding the speaking part, an analytic rubric was also devised for scoring this part of the test (see appendix 3). The rubric consisted of three dimensions against which the student's speaking skills were scored; i.e. vocabulary adequacy, structural accuracy, and phonological accuracy. Two raters participated in scoring each student's tape-recorded answer. They independently evaluated the student's speaking skills on the aforementioned dimensions. A student's score on this test was the average score given by the 2 raters. (For more details, see the rubrics of the rating scale). Accordingly, 20 marks are the maximum score of this part and the text maximum score is 80 marks.

\section{Validity and Reliability of the Test}

This test validity was established via showing it to a group of EFL university staff members working with this researcher. They reviewed the test items as regards suitability for measuring the general English language performance of preparatory year students. In addition, test reliability was decided on by piloting it on a group of EFL students (n=15) not included in this study. The test-retest method was used to calculate the reliability of this test. Results indicated that the reliability coefficient for the first part was 0.86, for the second part was 0.84, for the third part was 0.81 and for the fourth part was 0.82 . These coefficients shows that this instrument is internally consistent and reliable. Inter-rater reliability was also established for the speaking and writing parts of this test via rating ten answer tapes and ten written paragraphs, 
not included in the study, by this researcher and another rater. It was found 0.83 for the writing part and 0.80 for the speaking part. These values indicated a high inter-rater agreement. It was also found that the suitable time for finishing the first three parts of this test (reading, writing and listening) is 20 minutes for each part and 10 minutes for the last part (speaking). Therefore, a session of 70 Mins. were approved as the optimum time for completing the test.

\section{Pre-test}

On 14th September, 2015, this researcher started administering the test of general English language performance as a pre-test in order to assess students' general English language performance. The first two parts of the test, that assess reading and writing, were administered first followed by the third part that assesses listening comprehension. Next day, this researcher together with one of his trained colleagues started administering the fourth part of the test that assesses speaking skills. Assessing students' speaking skills lasted for about four successive days. This step was aimed to establish the equivalence of the study groups. An independent t-test was used to determine whether there was a statistically significant difference between mean scores of the students in the two groups. Results showed no statistically significant difference between the two groups of the study in the pre-assessment of general English language performance $(t=.36, p<0.05)$. This result assured the equivalence of the two study groups.

\section{Intervention}

On 29th September, 2015, this researcher started conducting this intervention. Upon planning for teaching the different lessons of the New Headway Plus: Special Edition, Beginner (2011), to the experimental group students, this researcher used Crabbe's (2007) list of learning opportunities that might arise from any particular task. Then, in a process, he calls 'adding private learning value', that treats language learning tasks as prompts and models for managing further learning, the different tasks presented in the student book were analyzed for 
identifying predetermined, as well as potential, affordances and learning opportunities. As a result, predetermined, as well as potential, affordances and learning opportunities were identified from these tasks out of this analysis. After that, specific private learning activities, based on Crabbe's (2003) learning opportunity framework, not prescribed by the structure of these tasks but expected to arise from the public part of each task, were predicted and added to the predetermined public activities of the lessons. Predicted activities and learning opportunities included those that may only apply to a small number (even just one) of the students, and those that may only happen if the lesson takes a specific direction or includes an optional stage.

An Example for this analysis for opportunity identification in task affordances is in task 6 of unit seven (My favourites) that requires students to pay attention to a given example and work quickly to complete the given task. The task requires students to correct the information about a famous football player they read about in the lesson. Incorrect information about that player was given in a short paragraph:

Alan is a journalist. New York is his favourite city. He loves it here. Next October he's in France for a game. He's married to an American woman. They have one daughter. Saturday is their favourite day.

When finished, students are asked to work in pairs and to compare the details. Next, the teacher plays a recording and gets students to check their answers.

After that, students are put in new pairs and asked to read the corrected text aloud (one reads the incorrect information and the other reads the correct). The teacher should be ready to drill difficult words and lines and to get students repeat the task. The correct information about that player are given in the following paragraph:

Alan is a football player. Barcelona is his favourite city. He loves it here. Next October he's in Germany for a game. He's married to a Spanish woman. They have two daughters. Monday is their favourite day. 
According to the activities prescribed (predetermined) by this task, students had the opportunity to practice reading a short paragraph, listening to a recording and retrieving prelearned information in the lesson. In addition, they had the opportunity of receiving help from the teacher with the difficult words they came across in the completion of this task.

Nevertheless, this task offered a range of unplanned learning opportunities, not provided by its structure, students were helped to see and to act on them:

1. Language input: students were helped to exploit the opportunity of listening to their teacher while he was giving instruction to complete the task and while he was explaining and drilling difficult words. They were also helped to exploit the opportunity of listening to their colleagues while reading aloud the corrected text.

2. Language output: Students were helped to produce and try out many jobs such as musician, actor, boxer, singer... and pianist in order to reach the correct answer which is football player. They were also helped to produce and try out many nationalities such as American, British, Canadian, Australian...and Danish to reach the correct nationality of Allan's wife which is Spanish. Students were also helped to exploit the opportunity of writing down the corrected information about Allan before saying them out loud to their colleagues.

3. Interaction: students had the opportunity to interact with their colleagues in the class while checking their answers. They also had the opportunity of interacting with their partners, giving and taking information, while completing this task. Students had the opportunity of using language in genuine situations as they were allowed to walk around freely and to chat for a bit about similar famous football players and information about them.

4. Feedback: students were helped to exploit the opportunity of using language in genuine exchanges of 
meaning via giving and taking feedback from their partners about the corrected information.

5. Rehearsal: students were helped to exploit the opportunity of rehearsing, among themselves, many words in order to reach the correct information and the opportunity of experimenting with different words and trying out the correct pronunciation and spelling of these words.

During teaching, adequate time besides flexibility were allowed for unplanned or predicted learning opportunities to happen. Students were helped to see the predicted private learning activities offered by the unplanned lesson affordances and to act on them independently under the teacher's management. All the time, the teacher was so sensitive to students' feelings, needs and responses. Many times when he felt that students find a different goal or perceive a different need, from the pre-planned ones, in a given activity or when they find a different meaning in the discourse created within that activity, he immediately took an action to change the direction or made unexpected language use. Information gaps that required students to communicate with each other to complete the tasks or to achieve the goals of the activities were created. Students were encouraged to use problem-solving skills, determine what data was missing, categorize and analyze together collected data, seek clarification from each other and collaborate to successfully achieve the goals.

In addition to the learning opportunities identified from the prescribed tasks, other productive diversions and learning opportunities were responded to, where appropriate, during the lesson. These opportunities included those that applied to only few students, and the opportunities that occurred when the lesson moved to another direction or included an elective step.

An example of those productive diversions and unplanned learning opportunities that were dealt with during this intervention was in teaching unit 10 (We had a great time). During teaching that unit, the teacher noticed that two students 
were whispering in the back. He did not take this as a threat to his authority or as evidence for impoliteness. Rather, he took it as a genuine learning opportunity. Having Crabbe's (2003) learning opportunity framework in mind, the teacher immediately stopped what he was doing and asked them to repeat what they were saying. One of them said that the theme of the unit reminded him of a bad time when a friend of him pulled a pack of cigarettes from his pocket and offered him one. Then, he took a tentative drag, filled his cheeks with smoke, and blew out. Since then, he couldn't give it up. Seamlessly, the teacher incorporated this content (smoking) into the classroom discussion, developed it and helped students to act on it. Students were invited to participate in a whole class discussion on the hazards of smoking. After that, they were asked to write a short paragraph on how to stop smoking. The teacher was ready, all the time, for providing level-appropriate scaffolding and language frameworks and for keeping a rich and relaxed environment that might stimulate more unplanned learning opportunities and unscripted communication. Students' agenda took over at many times throughout the intervention.

In light of this approach, the teacher's job changed from 'teaching to managing learning'. In addition, lesson 'aims', or 'learning outcomes' were substituted by 'learning opportunities'. That is, instead of describing what is expect of all learners to learn at the end of the lesson, emphasis was on what the students might attain as individuals learners.

Avoiding the struggle with the clock or with the time that has long been a serious issue that affects the success of the outcomes-grounded lessons, 'time frame' was used instead of 'timings'. For completing different lesson tasks and exercises, students were given a rough time.

At the end of each lesson, rather than assessing or describing the degree to which the lesson objectives were met, an appraisal of the quantity and quality of learning, both predicted and unpredicted, that actually occurred was conducted 
together with a reflection on how well this learning was facilitated.

\section{Post-test}

On $1^{\text {st }}$ November, 2015 , the participants of the study were given the test of general English language performance as a posttest for assessing their general English language performance after finishing the intervention.

\section{Results of the Study}

This section presents the results attained from this study. Results are presented in terms of the hypotheses of the study.

\section{Testing the Main Hypothesis of the Study}

T-test was used to test the main hypothesis of the study. Findings are shown in the following table:

Table 1: "T" value of the Cont. and Exp. Groups in the Posttest of General English Language Performance

\begin{tabular}{|c|c|c|c|c|c|}
\hline Group & $\mathrm{N}$ & $\mathrm{M}$ & SD & "T" value & Sig. \\
\cline { 1 - 4 } Cont. & $\mathbf{2 7}$ & $\mathbf{4 4 . 8 8 8 9}$ & $\mathbf{3 . 1 9 1}$ & & \\
\cline { 1 - 4 } Exp. & $\mathbf{3 0 . 6 0 0 0}$ & $\mathbf{3 . 7 4 7}$ & $\mathbf{- 5 . 1 2 *}$ & $\mathbf{0 . 0 0 0}$ \\
\hline
\end{tabular}

Table (1) shows that experimental group students' posttest scores are significantly higher than those of their counterparts of the control group in the post-test of General English Language Performance. The experimental group attained a higher mean score (49.6000) than that attained by their colleagues of the control group (44.8889). t-test results shows that $\mathrm{t}$-value $=(-$ 5.12) and this difference is significant at (.001) level. Thus, the main hypothesis of the study is confirmed.

\section{Testing the First sub-hypothesis}

T-test was used to test the first sub-hypothesis of the study. Findings are shown in the following table:

Table 2: "T" value of the Cont. and Exp. Groups in the Posttest of Reading Skill

\begin{tabular}{|c|c|c|c|c|c|}
\hline Group & $\mathrm{N}$ & $\mathrm{M}$ & SD & "T" value & Sig. \\
\cline { 1 - 4 } Cont. & 27 & 10.2222 & 2.792 & & \multirow{2}{*}{$-2.12^{* *}$} \\
\cline { 1 - 3 } Exp. & 30 & 11.7333 & 2.559 & 0.05 \\
\hline
\end{tabular}


Table (2) shows that experimental group students' posttest scores are significantly higher than those of their counterparts of the control group in the post-test of reading skill. The experimental group attained a higher mean score (11.7333) than that attained by their colleagues of the control group (10.2222). $\mathrm{t}$-test results shows that $\mathrm{t}$-value $=(-2.12)$ and this difference is significant at (.05) level. Thus, the first sub-hypothesis of the study is confirmed.

\section{Testing the Second sub-hypothesis}

T-test was used to test the second sub-hypothesis of the study. Findings are shown in the following table:

Table 3: "T" value of the Cont. and Exp. Groups in the Posttest of Writing Skill

\begin{tabular}{|c|c|c|c|c|c|}
\hline Group & N & M & SD & "T" value & Sig. \\
\hline Cont. & $\mathbf{2 7}$ & $\mathbf{1 2 . 9 2 5 9}$ & .917 & & \\
\cline { 1 - 3 } Exp. & $\mathbf{3 0}$ & $\mathbf{1 3 . 8 0 0 0}$ & $\mathbf{1 . 2 1 5}$ & $-3.08 * *$ & 0.05 \\
\hline
\end{tabular}

Table (3) shows that experimental group students' posttest scores are significantly higher than those of their counterparts of the control group in the post-test of writing skill. The experimental group attained a higher mean score (13.8000) than that attained by their colleagues of the control group (12.9259). t-test results shows that $\mathrm{t}$-value $=(-3.08)$ and this difference is significant at (.05) level. Thus, the second sub-hypothesis of the study is confirmed.

\section{Testing the Third sub-hypothesis}

T-test was used to test the third sub-hypothesis of the study. Findings are shown in the following table:

Table 4: "T" value of the Cont. and Exp. Groups in the Posttest of Listening Skill

\begin{tabular}{|c|c|c|c|c|c|}
\hline Group & $\mathbf{N}$ & $\mathbf{M}$ & SD & "T" value & Sig. \\
\hline Cont. & 27 & 10.6667 & 2.219 & & \\
\hline Exp. & 30 & $\overline{11.7333}$ & 2.333 & -1.77 & No \\
\hline
\end{tabular}

Table (4) shows no significant difference between the mean scores attained by students of the control and those of their counterparts in the experimental group in the post-test of the listening skill. Consequently, the third sub-hypothesis is rejected. 


\section{Testing the Fourth sub-hypothesis}

T-test was used to test the fourth sub-hypothesis of the study. Findings are shown in the following table:

Table 5: "T" value of the Cont. and Exp. Groups in the Posttest of Speaking Skill

\begin{tabular}{|c|c|c|c|c|c|}
\hline Group & N & M & SD & “T” value & Sig. \\
\hline Cont. & 27 & 11.0741 & 1.238 & & \\
\cline { 1 - 4 } Exp. & 30 & 12.3333 & 1.373 & $-3.64^{* *}$ & 0.05 \\
\hline
\end{tabular}

Table (5) shows that experimental group students' posttest scores are significantly higher than those of their counterparts of the control group in the post-test of speaking skill. The experimental group attained a higher mean score (12.3333) than that attained by their colleagues of the control group (11.0741). $\mathrm{t}$-test results shows that $\mathrm{t}$-value $=(-3.64)$ and this difference is significant at (.05) level. Thus, the fourth sub-hypothesis of the study is confirmed.

\section{Discussion of the Results}

While proving "cause and effect" in most intervention studies is very difficult, especially in the educational context, the results obtained from this study indicates that affordance-based teaching that utilizes various learning opportunities offered by language learning tasks is promising in an EFL context. According to the mean scores of the students in the experimental group on the posttest of general English language performance, affordance-based teaching is capable of improving students' overall performance in English language.

With respect to specific language skills, students in the experimental group outperformed their counterparts in the control one in almost all skills tested except for listening. Students of the experimental group showed an improved ability of reading for main ideas, as well as for details. They also displayed a better ability to write a paragraph with a clearly stated topic sentence and a concluding sentence, as well as reasonable supporting details. Their vocabulary use and their writing mechanics became better than their counterparts. Moreover, experimental group students became more willing to 
speak and to express themselves in intelligible utterances with correct vocabulary, appropriate use of stress and reasonable linking of words.

This improvement in experimental group students' language skills could be attributed to the effect of the affordancebased teaching used with them in this study. Being reactive to learning opportunities that arise during or as a consequence of the lesson, and not narrowly confined to pre-planned teaching points, this approach offered experimental group students several opportunities for developing their language skills. For example, students managed to engage in meaningful interaction, give and receive feedback about their performance, process comprehensible input, mentally rehearse or repeat specific aspects of performance, experiment with pronunciation and seek clarification. Through such unplanned learning activities, experimental group students developed their vocabulary use, their writing and reading skills. In addition, through oral practice with their colleagues, students gained self-confidence that enabled them to speak and express themselves. These results go in agreement with the results of many studies that concluded that activities such as classroom interaction, collaborative negotiated feedback, peer scaffolding and negotiation of meaning can improve students' reading (Aidinlou \& Tabeei, 2012; Sadeghi \& Sharifi, 2013), writing (Youhanaee, Tehrani \& Piri, 2012; Sabet, Tahriri \& Pasand, 2013; Marzban \& Sarjami, 2014) and speaking skills (Kasap, 2005; Lázaro-Ibarrola \& Azpilicueta-Martínez, 2015).

At the same time, these results assure Allwright's (2005) claim that what students can and might learn from a lesson is potentially much more richer than just the total amount of preplanned teaching points. Supporting this, Chick (2015) claims that good teaching "may not always be inextricably linked to rigid adherence to a pre-planned sequence of events" (p. 38). In the same vein, Shpancer (2004) states that assuming the ideal teacher role and forcing students to assume the concomitant student role is not conducive to learning. What is conducive to 
learning for him is a "live classroom, where students engage the material through dynamic interaction with each other and with the teacher" (p. 27).

Meanwhile, experimental group students achieved no superiority over their counterparts of the control group in listening comprehension. This may be due to the fact that the amount of native-speaker input received by the two groups of the study, as provided by the textbook, was the same. At the same time, it appears that despite its importance in the EFL classroom, non-native-speaker input mutually given and received among experimental group students had no significant effect on them and it did not help them to achieve superiority over their counterparts in taking this part of the test with nativespeaker input source. This result is in line with those of Bent and Bradlow (2003), Moinzadeh, Rezaei and Dezhara (2012) and Sadeghi and Zeinali (2014). These studies concluded that due to unfamiliarity with the phonological patterns, intonation...etc., listeners perform better on a listening test when they are listening to a speaker sharing the same L1 with them.

On the other hand, control group students had no private learning opportunities and they acted only on the public parts of the core book prescribed tasks. As usual, they had very limited opportunities to improvise, interact and receive and give feedback. In addition, they were rarely allowed to chat or to leave their places for a while. They adhere rigidly to a pre-planned sequence of events and most of the time they were there to help implement the teacher's pedagogical agenda. To this point, Cadorath and Harris (1998) add that:

An emphasis on lesson planning and the dominance of a course-book as a source of classroom activities, had unintended consequences in three specific areas; leading to the inhibition of interaction between the teacher and the student, the avoidance of genuine communicative opportunities available in unplanned language, and the loss of aspects of local knowledge and experience as topics for classroom talk ( $p$. 193). 
Supporting this, Miri and Qassemi (2015), claim that domineering teacher talk, extensive repair tightly initiated and controlled by the teacher, students' talk oriented toward teacherassigned tasks, limited wait-time, dearth of opportunities for the expression of personal feelings and ideas can be regarded as the main factors minimizing students' participation and consequently decreasing genuine learning opportunities in the EFL classroom.

\section{Recommendations and Suggestions for Further Research}

Based on the results obtained, some important recommendations related to English Language teaching and teachers are presented. The study findings indicate that affordance-based teaching is capable of improving students' overall English language performance. This means that is in proper foreign language teaching contexts, similar to those of the current study, affordance-based teaching could be incorporated with guaranteed success in foreign language classes.

EFL teachers need to change their own practices from teaching to managing learning; from teaching pre-planned specific teaching points to identifying and managing learning opportunities. Instead of basing their lesson plans on specific learning outcomes, they should plan for richness of opportunity. In addition, EFL teachers should overcome their fear of going off script and they should be prepared to cope with unexpected classroom events and help their students to act on them.

Further empirical studies are needed to provide evidences through practical application of the success of affordance-based teaching in the Egyptian context. It would be interesting to try affordance-based teaching with other foreign languages on an experimental basis. Besides, additional descriptive research is needed to pinpoint the attitudes of foreign language students, as well as teachers, towards the integration of affordance-based teaching into our foreign language classrooms. In conclusion, it is worth mentioning that this study is still a small scale one that 
does not allow the generalization of findings away from its population.

\section{References}

Alfaki, I. (2014). Sudan English language syllabus: Evaluating reading comprehension questions using Bloom's taxonomy. International Journal of English Language Teaching, 2(3), 53-74.

Alhamlan, S. (2013). EFL curriculum and needs analysis: An evaluative study. ERIC Document Reproduction Service No. 542860. Retrieved August 13, 2014, from: http://www.eric.ed.gov/contentdelivery/servlet/ERICServ let?accno=ED542860

Aljumah, F. (2011). Developing Saudi EFL students' oral skills: An integrative approach. English language Teaching, 4(3), 8489.

Anugerahwati, M. (2013). Let's use authentic materials, shall we? Paper presented at NELTAL Conference, March 30, 2013. Retrieved August 22, 2014, from: http://www.academia.edu/4036638/ ets Use Authentic Materials Shall We

Banegas, D. (2012). Teaching unplugged: Is Dogme an innovation or a remake? A paper presented at the 2012 SHARE CONVENTION, Buenos Aires, 26 July, 2012, Pp. 1-9. Retrieved August 22, 2014, from: http://www.academia.edu/2319484/Teaching unplugged Is Dogme an innovation or a remake

Bani Abdelrahman, M. (2014). An analysis of the tenth grade English language textbooks questions in Jordan based on the revised edition of Bloom's taxonomy. Journal of Education and Practice, 5(18), 139-152.

Brown, D. (2001).Teaching by principles: An interactive approach to language pedagogy. New York: Longman.

Cadorath, J., \& Harris S. (1998). Unplanned Classroom Language and Teacher Training. ELT Journal, 52(3), 188-195.

Celce-Murcia, M \& Olshtain, E. (2000). Discourse and context in language teaching. New York: Cambridge University Press. 
Charalambous, A. (2011). The role and use of course books in EFL. ERIC Document Reproduction Service No. 524247. Retrieved October 19, 2014, from: http://r.search.yahoo.com/ ylt=A0LEV1mvcRNUPq0AtRpX NyoA; ylu=X3oDMTEzMmdmMTEzBHNIYwNzcgRwb3MD MQRjb2xvA2ImMQR2dGlkA1NNRTQ4NV8x/RV=2/RE=141 0589232/RO=10/RU=http\%3a\%2f\%2ffiles.eric.ed.gov\%2ff ulltext\%2fED524247.pdf/RK=0/RS=c.7w9AYAKmDlkwKxC dUeqR8siaM-

Chappell, P. (2014). Engaging learners: Conversation- or dialogicdriven pedagogy? ELT Journal, 68(1), 1-11.

Coyle, Y., Yanez, L., \& Verdu, M. (2010). The impact of the interactive whiteboard on the teacher and children's language use in an ESL immersion classroom. System, 38, 614-625.

Cunningsworth, A. (1995). Choosing your coursebook. London: Macmillan Heineman.

Dailey, A. (2010). Difficulties implementing CLT in South Korea: Mismatch between the language policy and what is taking place in the classroom. Online Document. Retrieved August 22, 2014, from: https://www.google.com.eg/\#q =Difficulties+Implementing+CLT+in+South+Korea:+Mismatch+betw een+the+language +policy+and+what+is+taking+place $+\mathrm{in}+\mathrm{t}$ he+classroom

Delamont, S. (1976): Interaction in the classroom. London: Methuen \& Co Ltd.

Edwards, A. \& V. Furlong (1978): The Language of teaching. London: Heinemann Educational Book Ltd.

Elyas, T. \& Al Grigri, W. (2014). Obstacles to teaching English in Saudi Arabia public schools: Teachers' and supervisors' perceptions. International Journal of English Language Teaching, 2(3), 74-89.

Ghazal, S. \& Singh, S. (2014). Teaching unplugged: Applications of Dogme ELT in India. International Journal of English Language Teaching Studies, 2(1), 141-152.

Hammad, E. (2014). Palestinian EFL teachers' attitudes towards English textbooks used at the first three grades of 
elementary school. The Electronic Journal for English as a Second Language, 18(1). Retrieved October 18, 2014, from: http://www.tesl-ej.org/wordpress/issues/volume18/ej69 $\lfloor$ ej69a3/

Harmer J. (1998). How to teach English: An introduction to the practice of English language teaching. England: Longman. Herazo, R. (2010). Authentic oral interaction in the EFL class: What it means, what it does not. PROFILE, 12(1), 47-61. Jabeen, S. (2014). Implementation of communicative approach, English Language Teaching, 7(8), 68-74.

Kandil, A. (2009). Needs analysis and the Arab learners. TESOL Arabia/ Special Interest Groups/ LI-SIG Archives. Retrieved October 17, 2014, from: http://ilearn.20m.com/research/ needs.htm

Krashen, S. (1985). The input hypothesis: Issues and implications. New York: Longman.

Lazaraton, A. Teaching Oral Skills. In Celce-Murcia, M. (2001). Teaching English as a Second or Foreign Language. $3^{\text {rd }}$ edition. USA: Heinle \& Heinle.

Li, Q. (2007). Student and teacher views about technology: a tale of two cities? Journal of Research on Technology in Education, 39 (4), 377-397. Retrieved January 12, 2015, from:https://www.google.com.eg/\#q=Student+and+teache r+views+about+technology:+a+tale+of+two+cities\%3F

Long, M. (1983) Native speaker/normative speaker conversation and the negotiation of comprehensible input. Applied Linguistics, 4(1), 26-41.

Maslamani, J. (2013). Potential integration of a computermediated communication platform into the Saudi EFL classroom: A synthetic review. International Journal of Humanities and Social Science, 3(15), 73-78.

McCabe, D. (2005). Dogme: Online forum report. ELT Journal, 59(4), 333-335.

Meddings, L., \& Thornbury, S. (2009). Teaching unplugged: Dogme in English language teaching. Surrey, England: Delta Publishing. 
Mohr, K.J., \& Mohr, E.S. (2007, February). Extending Englishlanguage learners' classroom interactions using the response protocol. The Reading Teacher, 60(5), 440-450.

Parry, J. (2012).Teaching unplugged: The revitalization of ELT. Unpublished MA dissertation. The faculty of graduate and postdoctoral affairs, Carleton University, Ottawa, Ontario.

Rezaee, M. \& Farahian, M. (2012). An exploration of discourse in an EFL classroom: teacher talk. Procedia - Social and Behavioral Sciences, 47, 1237 - 1241.

Riazi, A. (2010). Evaluation of learning objectives in Iranian highschool and pre-university English textbooks using Bloom's taxonomy. 13(4). Retrieved June 15, 2014, from: http://www.tesl-ej.org/wordpress/issues/volume13/ej52 Lej52a5/

Richards, J. (2013). Curriculum approaches in language teaching: Forward, central, and backward design. RELC Journal, 44(1), 5-33.

Shah, K., Majeed, R., \& Ul-Waheed, S. (2013). Humanizing English textbooks evaluation at the higher secondary level in Pakistan. Language in India, 13(8), 481-499.

Shahin, V., \& Ehsan A. (2014). Implementing CLT in the Iranian context: "Reality" versus Theory. Procedia - Social and Behavioral Sciences, 98, 1905-1911.

Stewart, D. (2008). Technology as a management tool in the community college classroom: Challenges and benefits. MERLOT Journal of Online Learning and Teaching, 4(4), 459468.

Tomlinson, B. (2012). Materials development for language learning and teaching. Language Teaching, 45(2), 143-179.

Thornbury, S. \& Meddings, L. (2001). The roaring in the chimney (or: What coursebooks are good for). Humanising Language Teaching, 3(5). Retrieved December 18, 2014, from: http://www.hltmag.co.uk/sep01/sart8.htm

Thornbury, S. (2011). A Dogma for EFL. SHARE: A Electronic Magazine. Retrieved September, 17, 2014, from: http:// www. shareeducation.com.ar/pastissues3/222/1.htm 
Van Lier, L. (1996). Interaction in the language curriculum: Awareness, autonomy, and authenticity. London: Longman.

Xerri, D. (2012). Experimenting with Dogme in a mainstream ESL context. English Language Teaching, 5(9), 59-65.

Weiss, K. (2009). Low-no tech teaching: What we lose on the smart classroom. Perspectives Electronic Journal of the American Association of Behavioral and Social Sciences, 12. Retrieved October 16, 2014, from: http://www.unco.edu/ AE-Extra/2010/5/weiss.html

Worth, A. (2013). A Dogme based approach from the learners' perspective. The Journal of Kanda University of International Studies, 24(1), 77-99.

$\mathrm{Yu}, \mathrm{R}$. (2008). Interaction in EFL classes, Asian social sciences, $4(4), 48-50$.

Zhang, S. (2009). The role of input, interaction and output in the development of oral fluency. English Language Teaching, 2(4), 91-100. 
